\title{
Genome-wide association analysis of seedling traits in diverse Sorghum germplasm under thermal stress
}

\author{
Ratan Chopra*, Gloria Burow ${ }^{*}$ (D), John J. Burke, Nicholas Gladman and Zhanguo Xin
}

\begin{abstract}
Background: Climate variability due to fluctuation in temperature is a worldwide concern that imperils crop production. The need to understand how the germplasm variation in major crops can be utilized to aid in discovering and developing breeding lines that can withstand and adapt to temperature fluctuations is more necessary than ever. Here, we analyzed the genetic variation associated with responses to thermal stresses in a sorghum association panel (SAP) representing major races and working groups to identify single nucleotide polymorphisms (SNPS) that are associated with resilience to temperature stress in a major cereal crop.
\end{abstract}

Results: The SAP exhibited extensive variation for seedling traits under cold and heat stress. Genome-wide analyses identified 30 SNPs that were strongly associated with traits measured at seedling stage under cold stress and tagged genes that act as regulators of anthocyanin expression and soluble carbohydrate metabolism. Meanwhile, 12 SNPs were significantly associated with seedling traits under heat stress and these SNPs tagged genes that function in sugar metabolism, and ion transport pathways. Evaluation of co-expression networks for genes near the significantly associated SNPs indicated complex gene interactions for cold and heat stresses in sorghum. We focused and validated the expression of four genes in the network of S606g025040, a basic-helix-loop-helix (bHLH) transcription factor that was proposed to be involved in purple color pigmentation of leaf, and observed that genes in this network were upregulated during cold stress in a moderately tolerant line as compared to the more sensitive line.

Conclusion: This study facilitated the tagging of genome regions associated with variation in seedling traits of sorghum under cold and heat stress. These findings show the potential of genotype information for development of temperature resilient sorghum cultivars and further characterization of genes and their networks responsible for adaptation to thermal stresses. Knowledge on the gene networks from this research can be extended to the other cereal crops to better understand the genetic basis of resilience to temperature fluctuations during plant developmental stages.

Keywords: Sorghum association panel, Genome wide association, Thermal stress, Temperature resilience, Anthocyanin, Gene network

\footnotetext{
* Correspondence: ratan.chopra@ars.usda.gov; gloria.burow@ars.usda.gov Plant Stress \& Germplasm Development Unit, Cropping Systems Research Laboratory, USDA-ARS, Lubbock, TX 79415, USA
} 


\section{Background}

Temperature fluctuations during the growing seasons of a crop critically affect plant development and adversely influence the crop production [1]. For example at seedling stage, chilling temperatures slow down growth, generally as a result of reduced enzymatic activities [2, 3], while high temperatures can accelerate growth but with longer exposure has detrimental effects on viability and growth [4]. High temperature stresses induces reactive oxygen species (ROS) production, resulting in oxidative damage and cell death [5]. Impacts of thermal stresses reinforce the need to understand how underlying genetic variation affects the response of major crops to a range of thermal stress, and how genetic diversity can be utilized to develop germplasm with greater fitness against temperature fluctuations.

The introduction and breeding of traits for improved tolerance to abiotic stress is of continuous interest in cereal crops such as sorghum, maize, wheat, and barley for the purposes of sustained production. This has become more necessary in a cereal crop such as sorghum, which is likely cultivated under marginal conditions and thermal stresses. Improving cold stress tolerance in sorghum seedlings will be advantageous for early-season planting and to provide robust stand establishment, whereas heat tolerance can improve the survivability of seedlings during periodic high temperature that occurs in the regular planting season in the US sorghum belt.

Cool ambient air and soil temperatures are major abiotic stressors affecting plant growth and development, and are of great importance in northern latitudes such as USA, Europe and China. Cold stress is known to induce the biosynthesis of flavonoids, anthocyanins, and phenylpropanoids [6]. Anthocyanin content in leaf was reported to be positively correlated with cold tolerance in some Arabidopsis ecotypes [7]. Higher levels of anthocyanin, proposed as the blue light absorbing flavonols in the leaf, ensure that chlorophyll is not over-excited under extreme conditions of cold [8-10], suggesting role of anthocyanin as defense machinery against the cold-induced damage. In sorghum, variation for cold tolerance at genetic level is being evaluated through bi-parental mapping $[11,12]$ and association mapping approaches [13]. However, the link between cold response and anthocyanin level in sorghum has not been explored to date.

Similarly, heat stress limits the growth and development of sorghum seedling at high temperature $\left(30-40{ }^{\circ} \mathrm{C}\right)$ by further inhibiting photosynthesis [14, 15]. A short period of heat stress is sufficient to provoke severe cellular injury. Chlorophyll synthesis is sensitive to heat stress and is an indicator of heat-stress induced injury. In plants, heat is a major abiotic instigator for the accumulation of ROS, which are detrimental to plant cells causing damage to valuable biomolecules like sugars, lipids, and membranes
[16]. Heat tolerant cultivars would be a key improvement for breeding programs to address the adverse effects of abiotic stress on crops $[17,18]$. Variation for tolerance to heat stress is observed in sorghum but this remains to be analyzed for use in selection and breeding.

Both cold and heat tolerance are complex quantitative traits, involving multiple regulatory gene mechanisms and metabolic pathways. Therefore, it is important to analyze primary or secondary metabolites along with the morphological and physiological traits such as seedling weight and length that varies with thermal stress conditions. In corn, association studies using seedling traits and chlorophyll phenotypic evaluations were performed in panels to identify QTL and SNP that conditions cold tolerance in seedlings [19]. Further, genetic and molecular basis for cold and heat tolerance traits are necessary to understand the mechanisms and gene regulatory networks underlying tolerance traits at seedling stages in sorghum.

Understanding such complex and coordinated networks requires an establishment of genomic resources for abiotic stress tolerance traits using integrated genomics approach of associating mapping, bi-parental mapping and expression analysis. Whole-transcriptome sequencing can help in constructing putative transcriptional networks; and few studies in sorghum have elucidated differential expression patterns under cold [20], drought [21, 22], and nitrogen stress [23]. Genome-wide gene expression analysis has recently aided in dissecting the impacts of abiotic stress at the molecular level. However, the high abundance of the differentially expressed genes makes it harder to find most critical genes involved in stress defense for a particular genotype. Thus knowledge of the impact of genetic variation on stress response can be improved by combining prior molecular information through genetics (bi-parental/association mapping) in combination with transcriptional networks generated from RNASeq data.

In sorghum, association mapping has been employed to identify association between genome regions or hot spots in the form of single nucleotide polymorphism and different traits, including grain quality [24], plant height [25], stalk rot [26], grain flavonoid pigmentation traits [27], seed size [28], dhurrin content [29], and cold germination [13]. Most of these studies reinforce that association mapping has proved as a powerful approach for dissecting complex traits in sorghum. Therefore a detailed analysis of association between seedling morphophysiological and metabolite responses to cold and heat stresses, and that of specific genome regions of interest will be highly useful in developing molecular markers for stress-tolerance and is anticipated to enhance the efficiency of traditional breeding programs.

In this study, 300 diverse accessions of sorghum were used to conduct association analysis of seedling 
Table 1 Summary statistics expressed as mean and heritability for traits evaluated for genome wide association studies of the sorghum associaiotn panel under stress at seedling stage. Evaluation of analysis of variance is included in the table to assess the contributionof genotypes

\begin{tabular}{|c|c|c|c|c|c|}
\hline \multirow[b]{2}{*}{ Thermal stress } & \multirow[b]{2}{*}{ Traits Measured } & \multirow[b]{2}{*}{ Mean $( \pm S D)$} & \multirow[b]{2}{*}{ Heritability } & \multicolumn{2}{|c|}{ Analysis of Variance } \\
\hline & & & & Sums of Squares & Mean Squares \\
\hline \multirow[t]{5}{*}{ Cold Stress } & Shoot weight (mg) & $41.00( \pm 12.00)$ & 0.38 & 34,068 & $119.959^{* * *}$ \\
\hline & Root weight (mg) & $35.00( \pm 15.00)$ & 0.32 & 73,015 & $257.096^{* * *}$ \\
\hline & Shoot length (cm) & $49.48( \pm 10.56)$ & 0.44 & 28,899 & $101.760^{* * *}$ \\
\hline & Root length $(\mathrm{cm})$ & $105.46( \pm 23.67)$ & 0.61 & 139,911 & $492.647^{* * *}$ \\
\hline & Anthocyanin levels (abs at $530 \mathrm{~nm} / \mathrm{shoot}$ fresh weight - mg) & $7.00( \pm 5.00)$ & 0.60 & 7,482 & $26.348^{* * *}$ \\
\hline \multirow[t]{7}{*}{ Heat Stress } & Shoot weight (mg) & $40.00( \pm 13.00)$ & 0.47 & 46,670 & $164.334^{* * *}$ \\
\hline & Root weight (mg) & $32.00( \pm 13.00)$ & 0.53 & 50,503 & $177.828^{* * *}$ \\
\hline & Shoot length $(\mathrm{cm})$ & $51.51( \pm 15.02)$ & 0.47 & 64,049 & $225.526^{* * *}$ \\
\hline & Root length $(\mathrm{cm})$ & $124.26( \pm 28.59)$ & 0.39 & 239,073 & $841.807^{* * *}$ \\
\hline & Chlorophyll A (abs at $663 \mathrm{~nm} /$ shoot fresh weight - mg) & $32.87( \pm 21.26)$ & 0.52 & 104,161 & $384.361^{* * *}$ \\
\hline & Chlorophyll B (abs at $646 \mathrm{~nm} /$ shoot fresh weight - mg) & $10.72( \pm 6.63)$ & 0.49 & 9,957 & $36.742^{* * *}$ \\
\hline & Total Chlorophyll (abs at $470 \mathrm{~nm} / \mathrm{shoot}$ fresh weight - mg) & $43.58( \pm 27.72)$ & 0.52 & 175,359 & $647.084^{* * *}$ \\
\hline
\end{tabular}

***- statistically significant $-p$-value of 0.0001

phenotypic variation during cold and heat stress treatments with the aim to highlight genetic differences that conditions adaptation to thermal stress. A detailed analysis of the genes present in the QTL regions was carried out to identify candidate genes involved in adaptation to cold and heat stress. Specifically, the SNPs associated with the cold stress traits were validated in a set of genotypes with different tolerance to determine the haplotypes. The expression networks were also evaluated to elucidate putative pathway for thermal stress tolerance.

\section{Results and discussion}

\section{Phenotypic variation and correlations among the cold and heat response traits}

The summary of statistics of the phenotypic data gathered in this study indicated that the different germplasm of sorghum association panel displayed wide range of diversity both under cold and heat stress (Table 1). The heritability values ranged from moderate $(0.32$ to 0.44$)$ for a number of seedling traits and high for root and anthocyanin under cold stress (Table 1). The heritability for morpho-physiological traits measured under heat stress was also in the moderate range of $0.39-0.53$ (Table 1). The analysis of variance showed that genotypes are significantly different for all traits analyzed (Table 1). Genotypes explained the largest proportion of variance among all sources of variation.

The level of variation observed for various traits assessed is reflected in the histograms under cold and heat stress (Figs. 1, 2). Notably, under cold stress the correlation between the traits was higher in shoot and root measurements while the correlation of anthocyanin levels with the others traits (including root and shoot features) were moderate and ranged only from 0.142 to 0.305 (Fig. 1). The correlation analysis among the traits under heat stress was also performed (Fig. 2). Seven traits under heat stress treatment had significant correlations, which ranged from 0.451 to 0.997 between each other. However, the comprehensive Pearson correlation analysis of traits between cold and heat stress showed less significant correlations between each other (Additional file 1), indicating that sorghum seedlings exhibited different responses under these two temperature stress conditions at phenotypic or biochemical levels.

These results suggest that the observed genetic variations underlying cold and heat stress responses at the seedling stage are biologically meaningful. Thus, molecular markers associated with the traits could be applicable in sorghum breeding for improving cold and heat tolerance separately.

\section{Genome-wide association analysis under cold and heat stress}

Early-season cold and heat tolerance of sorghum seedlings is a pre-requisite for better crop establishment. Several methods have been used to determine early stage cold tolerance in sorghum [12, 13, 30-32] and Gosavi et al. [19] has assessed heat tolerance of sorghum seedlings for a few genotypes. However, no significant efforts have been made to dissect the genetic mechanisms for heat tolerance of seedlings using large populations or germplasms in sorghum. Broad variability for germination and emergence is a great advantage in breeding sorghum for adaptation $[11,12]$, therefore we used a SAP to assess the variability among sorghum genotypes and find association for the traits measured under both stresses. 


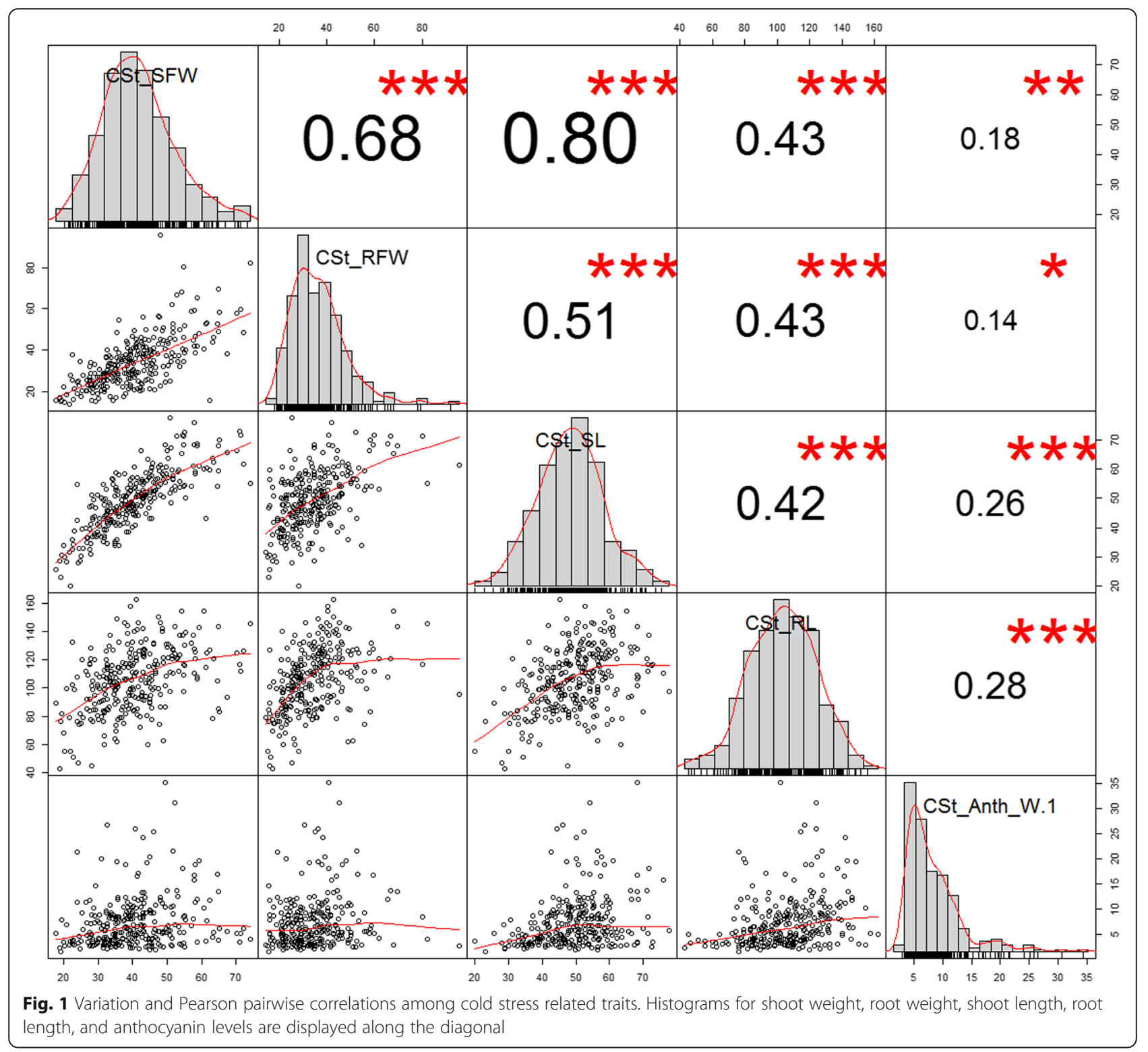

To understand whether there is common allelic variation that could explain differences under thermal stresses, we utilized community resource genotype data for the SAP [33] (www.morrislab.org/data). A total of 265,487 SNPs were utilized for GWAS with the seedling traits data under controlled thermal stress. The phenotypic data for five and seven seedling traits for cold and heat stress respectively, utilized for the analysis are provided in the Additional file 2.

For cold stress, we evaluated five different traits which included shoot length, shoot weight, root length, root weight, and anthocyanin content followed by association analysis for these traits with $265 \mathrm{~K} \mathrm{SNPs} \mathrm{(Fig.} \mathrm{3).} \mathrm{A} \mathrm{total}$ of 30 SNPs were significantly associated with the five traits measured with FDR values $\leq 0.03$ (Table 2). Ten SNPs were significantly associated with anthocyanin content of fresh leaf and 13 SNPs were significantly associated with the root length (Table 3). Notably, the significant SNPs that indicate marker-trait associations (MTA) for the anthocyanin content and root length were observed mainly on Chr02 and Chr06 (Fig. 3). Associations for shoot length (5), shoot weight (1) and root weight (1) were found mostly on Chr03 and Chr06 (Fig. 3).

Previous studies in sorghum and other crops have suggested a role for root traits (Bekele et al. [31]; Balota et al. [30]) and anthocyanin levels (Marczak et al. [7]; Hannah et al. [8]) during chilling stress response in sorghum. Recent findings and reports suggested that root establishment could be one of the most important factors for field establishment, next to that of field germination [31]. Furthermore, root biomass under controlled conditions was correlated with the seedling vigor under field 


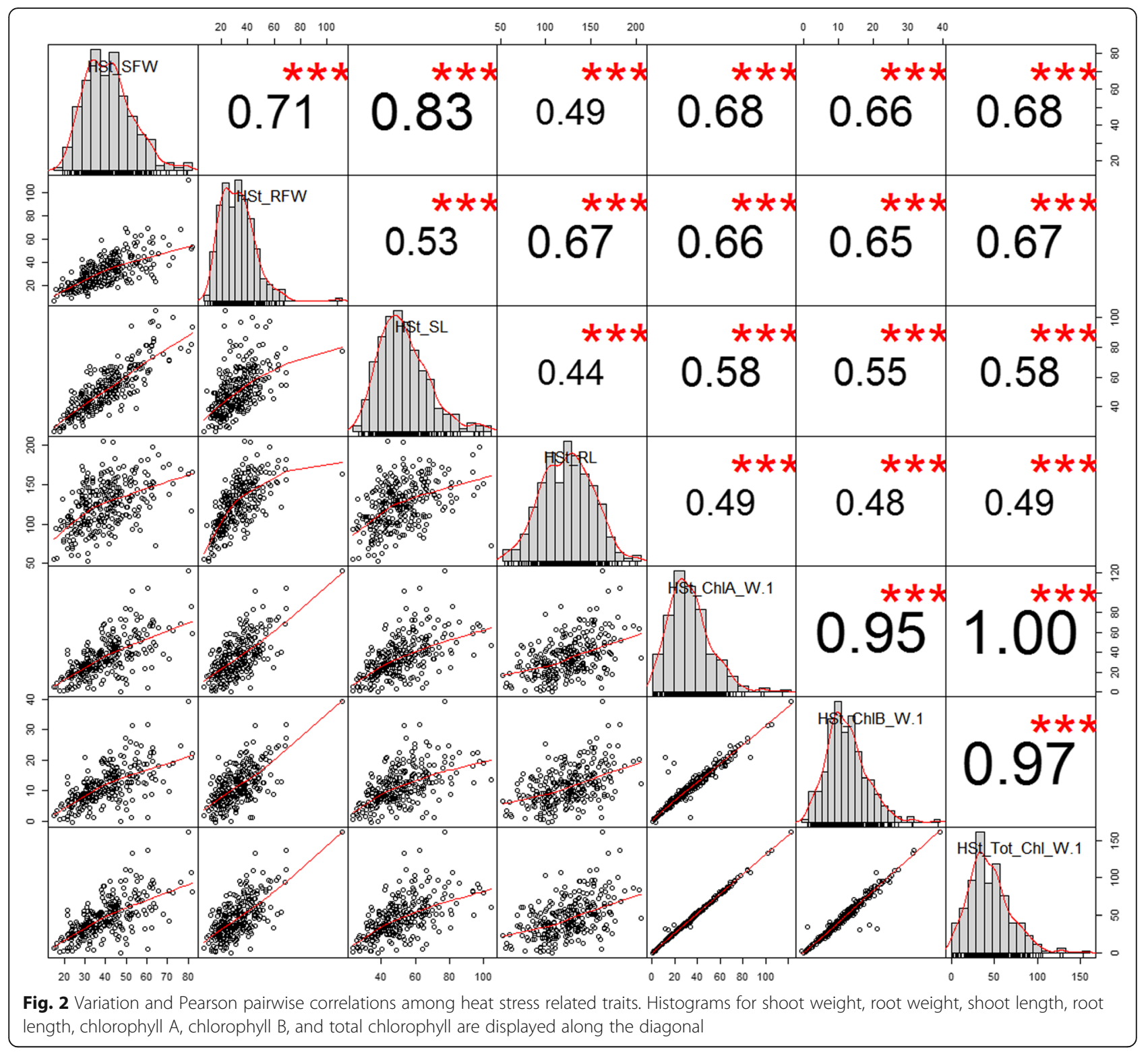

conditions [35]. Related studies suggest that root traits could influence the stay-green phenotype and seed yield in sorghum [36]. The significant associations of SNPs for root traits observed in the current study could indicate the possible role of genes tagged by such SNPs in adaptation or tolerance to chilling stress. The establishment of specific SNPs with positive contribution to robust root growth and actual seedling growth under cold temperatures would be beneficial in aiding selection of desirable germplasm with cold stress tolerance during screening with large number of accessions via markerassisted selection.

The heat stress on sorghum seedlings showed association for shoot traits, but none were detected for the root measurements (Table 2). The SNPs identified for shoot fresh weight were present on Chr02, Chr05 and
Chr06 with 5 SNPs belonging to the same gene on Chr02 (Fig. 4). Associations for shoot fresh weight explained 10-15\% variation in the population and for shoot length from 8 to $25 \%$ variation (Table 4). Variation in shoot traits caused by higher temperature suggest that possible favorable alleles in a number of accessions could accelerate the growth, while other haplotypes could have negative effect of retarding plant development under heat stress. It was reported that high temperatures accelerate growth but with longer exposure, viability of seedlings declined [37]. Chlorophyll measurements during heat stress showed significant associations with two SNPs which were present on Chr04, and for shoot length significant SNPs were localized on Chr03 (1) and Chr06 (2) (Fig. 4). 


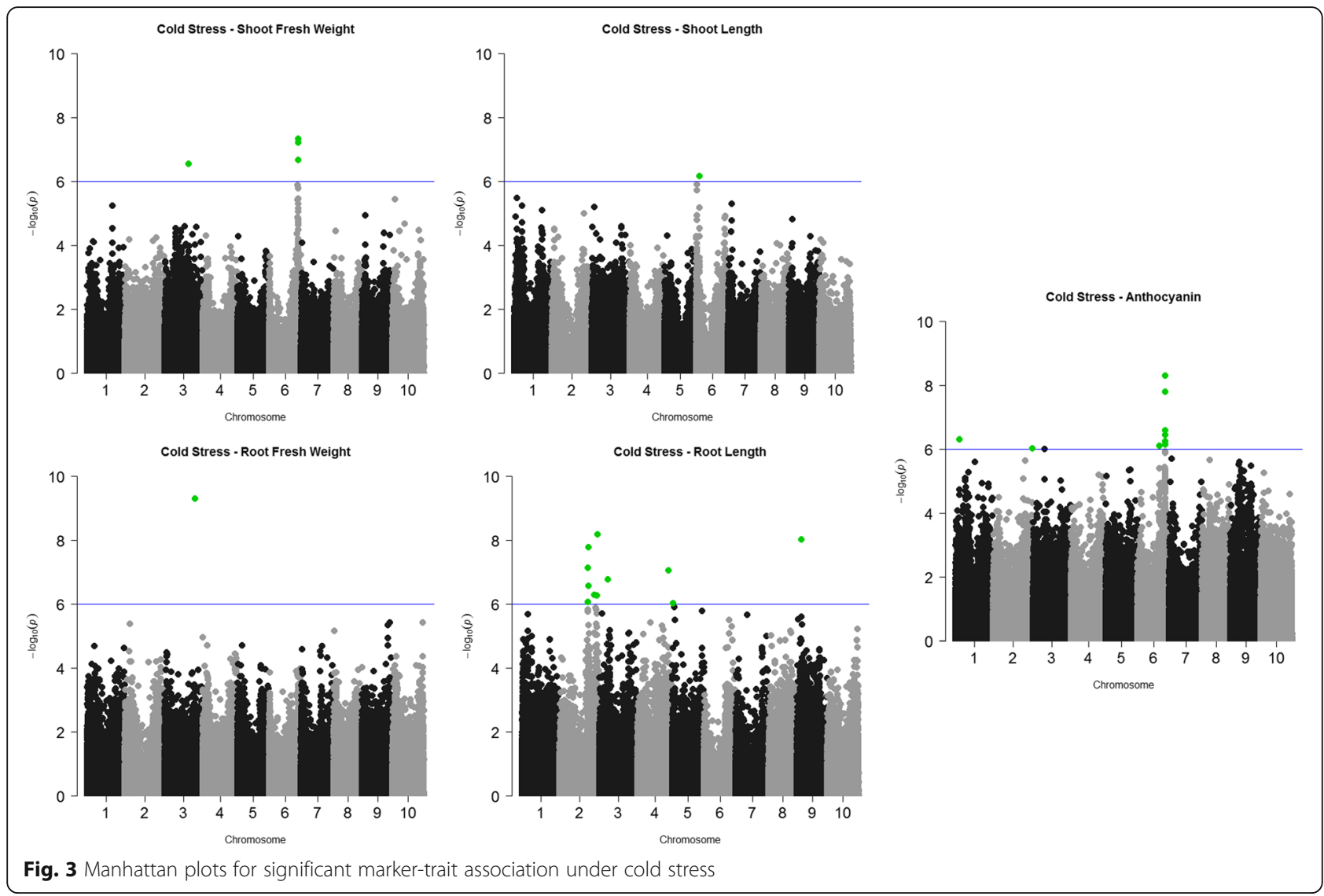

Table 2 List of the numbers of significant association for the traits measured under both heat and cold stress including the lowest probability value and false discovery rate (FDR) analysis

\begin{tabular}{|c|c|c|c|}
\hline Trait (and designation) & $\begin{array}{l}\text { Number of significantly associated } \\
\text { SNPs* }\end{array}$ & Lowest $P$-value & Lowest FDR Adjusted values \\
\hline Cold stress - shoot weight (CSt_SFW) & 5 & 4.69E-08 & 0.0081 \\
\hline Cold stress - root weight (CSt_RFW) & 1 & $5.11 \mathrm{E}-10$ & 0.0001 \\
\hline Cold stress - shoot length (CSt_SL) & 1 & $6.99 \mathrm{E}-07$ & 0.1709 \\
\hline Cold stress - root length (CSt_RL) & 13 & $6.60 \mathrm{E}-09$ & 0.0012 \\
\hline Cold stress - anthocyanin levels/weight(CSt_Anth_W $\left.{ }^{-1}\right)$ & 10 & 4.89E-09 & 0.0012 \\
\hline Total & 30 & & \\
\hline Heat stress - shoot weight (HSt_SFW) & 7 & 2.39E-07 & 0.0158 \\
\hline Heat stress - root weight (HSt_RFW) & - & - & - \\
\hline Heat stress - shoot length (HSt_SL) & 3 & 4.56E-07 & 0.0702 \\
\hline Heat stress - root length (HSt_RL) & - & - & - \\
\hline Heat stress - Chlorophyll A/fresh weight (HSt_ChIA_W ${ }^{-1}$ ) & - & - & - \\
\hline Heat stress - Chlorophyll B/fresh weight (HSt_ChIB_W ${ }^{-1}$ ) & 2 & 4.50E-07 & 0.119 \\
\hline Heat stress - Total chlorophyll/fresh weight (HSt_Tot_Chl_W'-1) & - & - & - \\
\hline Total & 12 & & \\
\hline
\end{tabular}

*Total number of significantly associated SNPs with the traits measured during thermal stresses at $p$-value of $1 \mathrm{E}-06$ 
Table 3 List of significant SNP associations, the genes tagged by significant SNPs and information from the genome wide analysis of sorghum germplasm under cold stress at seedling stage

\begin{tabular}{|c|c|c|c|c|c|c|}
\hline Trait & SNP & FDR Adjusted $p$-Values* & $\mathrm{R}^{2}$ Value ** & Nucleotide Variation & Distance to nearest gene $(\mathrm{bp}) * * *$ & Nearest Gene ID \\
\hline CSt_SFW & S6_57170126 & 0.008 & 10.73 & $\mathrm{C} / \mathrm{G}$ & $(-) 588$ & Sb06g028380 \\
\hline CSt_SFW & S6_57163269 & 0.008 & 10.26 & $A / G$ & 149 & Sb06g028370 \\
\hline CSt_SFW & S6_57302179 & 0.015 & 10.30 & $\mathrm{~T} / \mathrm{C}$ & 0 & Sb06g028540 \\
\hline CSt_SFW & S6_57163127 & 0.015 & 12.62 & $A / G$ & 291 & Sb06g028370 \\
\hline CSt_SFW & S3_47228001 & 0.015 & -17.48 & $\mathrm{~T} / \mathrm{C}$ & 1973 & Sb03g023720 \\
\hline CSt_RFW & S3_59699677 & 0.000 & 0.06 & T/A & 930 & Sb03g031320 \\
\hline CSt_SL & S6_5762763 & 0.171 & 8.75 & T/A & 768 & Sb06g002877 \\
\hline CSt_RL & S2_73739699 & 0.001 & -20.80 & T/A & $(-) 127$ & Sb02g039680 \\
\hline CSt_RL & S9_8614594 & 0.001 & -14.86 & $\mathrm{G} / \mathrm{A}$ & 2098 & Sb09g006020 \\
\hline CSt_RL & S2_56602226 & 0.001 & -12.79 & $\mathrm{G} / \mathrm{A}$ & 543 & Sb02g023140 \\
\hline CSt_RL & S2_54575799 & 0.005 & 11.99 & $A / G$ & $(+) 889$ & Sb02g022120 \\
\hline CSt_RL & S4_60946340 & 0.005 & -25.13 & $\mathrm{G} / \mathrm{C}$ & 569 & Sb04g030940 \\
\hline CSt_RL & S3_16201529 & 0.008 & -16.12 & $\mathrm{G} / \mathrm{C}$ & 495 & Sb03g013220 \\
\hline $\mathrm{CSt} \_\mathrm{RL}$ & S2_56566217 & 0.010 & 12.65 & $C / G$ & $(+) 398$ & Sb02g023120 \\
\hline CSt_RL & S2_67807062 & 0.015 & -12.04 & C/A & - & - \\
\hline CSt_RL & S2_72583772 & 0.015 & 14.48 & $C / T$ & $(+) 2810$ & Sb02g038300 \\
\hline CSt_RL & S2_72833569 & 0.015 & 12.10 & $C / T$ & $(+) 2150$ & Sb02g038630 \\
\hline CSt_RL & S2_54593968 & 0.019 & 13.13 & $A / G$ & $(-) 156$ & Sb02g022140 \\
\hline CSt_RL & S2_54593969 & 0.019 & 13.13 & $A / G$ & $(-) 157$ & Sb02g022140 \\
\hline CSt_RL & S5_1302419 & 0.019 & 5.84 & $\mathrm{C} / \mathrm{G}$ & $(+) 66$ & Sb05g001215 \\
\hline CSt_Anth_W ${ }^{-1}$ & S1_8039999 & 0.022 & -42.27 & $\mathrm{G} / \mathrm{T}$ & $(-) 104$ & Sb01g009310 \\
\hline CSt_Anth_W ${ }^{-1}$ & S6_53967668 & 0.001 & -5.71 & $\mathrm{~T} / \mathrm{C}$ & 77 & Sb06g024943 \\
\hline CSt_Anth_W ${ }^{-1}$ & S6_54057566 & 0.002 & -19.29 & $\mathrm{G} / \mathrm{C}$ & $(+) 2144$ & Sb06g025060 \\
\hline CSt_Anth_W ${ }^{-1}$ & S6_53978420 & 0.022 & -20.33 & $\mathrm{G} / \mathrm{C}$ & 661 & Sb06g024960 \\
\hline CSt_Anth_W ${ }^{-1}$ & S6_54030245 & 0.017 & -13.36 & $\mathrm{G} / \mathrm{A}$ & $(-) 440$ & Sb06g025040 \\
\hline CSt_Anth_W ${ }^{-1}$ & S6_53848121 & 0.023 & -5.18 & $\mathrm{~T} / \mathrm{C}$ & $(+) 4385$ & Sb06g024820 \\
\hline CSt_Anth_W ${ }^{-1}$ & S6_53791123 & 0.019 & 5.21 & $\mathrm{~T} / \mathrm{C}$ & (+)2883 & Sb06g024740 \\
\hline CSt_Anth_W ${ }^{-1}$ & S6_43169342 & 0.023 & -47.53 & $\mathrm{~A} / \mathrm{G}$ & 108 & Sb06g015560 \\
\hline CSt_Anth_W ${ }^{-1}$ & S6_54030254 & 0.017 & 13.36 & $\mathrm{G} / \mathrm{T}$ & $(-) 449$ & Sb06g025040 \\
\hline CSt_Anth_W ${ }^{-1}$ & S2_76203986 & 0.025 & 36.77 & $C / T$ & $(-) 2259$ & $S b 02 g 042450$ \\
\hline
\end{tabular}

*False Discovery Rate (FDR) values for the significantly associated SNP at $p$-value of 1E-06

**Percent trait variation explained by the associated SNPs

***Distance to the nearest annotated gene coordinates in the reference genome

The total chlorophyll content measured under heat stress provided association with SNP S4_48000182 and S4_48000349 explaining 20\% variance. Associations with the chlorophyll content under heat stress were less significant as compared to the other traits. It is generally accepted that chlorophyll biosynthesis is highly sensitive to heat stress. To confer tolerance to heat-stress induced injury variations among genes involved in the biosynthetic pathway may provide protective mechanisms.

Notably, SNP associated with a number of seedling traits during thermal stress were linked to the variations in sorghum Chr06. For example, anthocyanin content trait (CSt_Anth_W $\left.{ }^{-1}\right)$ during cold stress had eight SNP markers localized on Chr06, and shoot seedling traits under heat and cold stresses also, had eight SNPs localized on Chr06 (Table 3 and 4). A number of significant regions in Chr06 has previously been implicated in other stress tolerance such as ergot resistance [38], drought tolerance [36], sugar metabolism [39], and contrasting photoperiod conditions [40]. These results indicate an important role of genes in Chr06 in sorghum growth and development under various environmental conditions making it an interesting focus for studies of selection. 


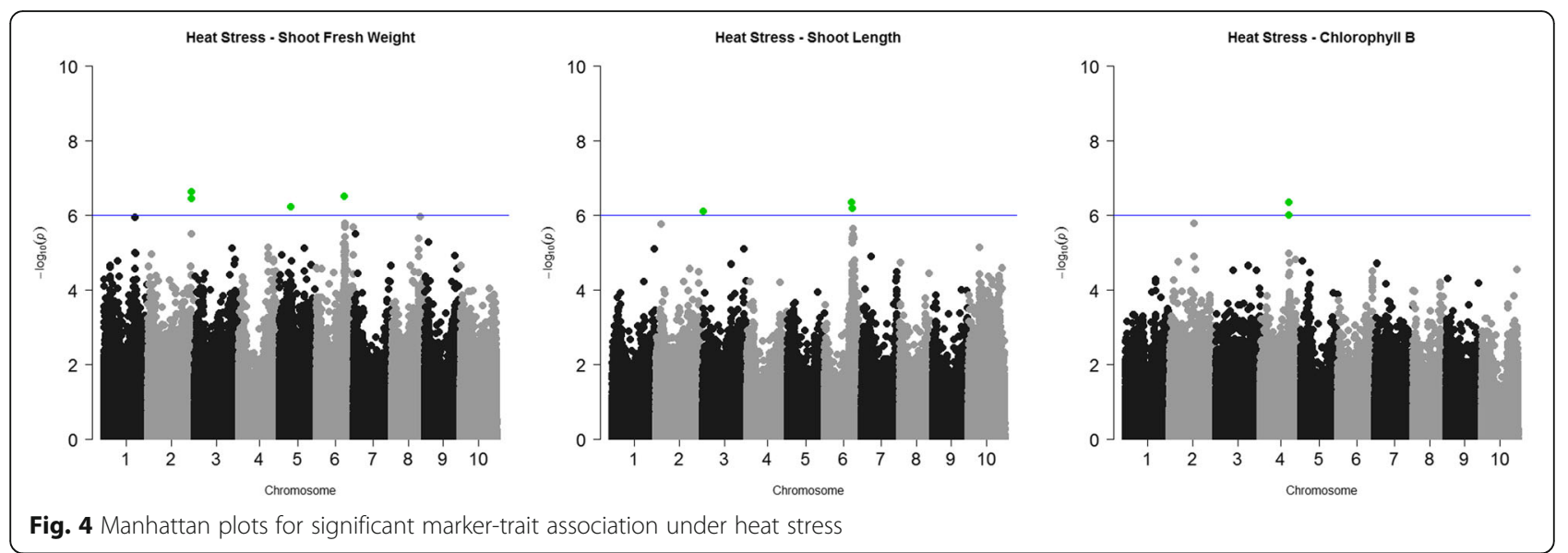

Genome scans for candidate genes near significant SNPs Majority of the SNPs associated with the traits subjected to thermal stresses were either within the gene or a few thousand nucleotides apart. Notably, the resolution of such strong linkage to trait-responsible genes could be possible in our GWAS study because of distinct quantitative measures of response to thermal stress as compared to indirect measures in other studies. Thirty-three putative genes near the 43 associated loci were identified and are presented with gene annotations including possible functions, in Table 5.

For cold stress conditions, we found that some genes were annotated as transcription factors and others belong to metabolic biosynthesis or transport. Two bHLH transcription factors, Sb06g025040 and Sb06g0254060 belong to an anthocyanin regulatory mechanism and were associated with the anthocyanin levels measured under cold conditions. Transcription factors such as $b H L H$ are suggested to be involved in stress-adaptive mechanisms; recent studies have shown the role of such transcription factors at least in part to cold tolerance, by positively regulating ROS removal [41-43]. Similarly, Sb03g031320, a C2H2 zinc finger protein with a putative splicing function, is associated with root fresh weight under cold conditions. Zinc finger proteins are also involved in regulating tolerance mechanisms under oxidative stresses [44], and more recently a study showed increases in fresh weight and root length upon cold stress compared to wild-type with the transformation of $\mathrm{C} 2 \mathrm{H} 2$ domain gene in Arabidopsis [45]. Other transcription factors such as Sb06g024820 and Sb05g001215 were also associated with anthocyanin level and root length, respectively. These genes along with the regulatory transcription factors could be involved in membrane stability and tolerance to cold stress.

One of the significant QTLs on Chr06 (S6_54057566) co-localizes with a gene identified in a previous study for

Table 4 List of significant SNP associations, the genes tagged by significant SNPs and information from the genome wide analysis of sorghum germplasm under heat stress

\begin{tabular}{|c|c|c|c|c|c|c|}
\hline Trait & SNP & FDR Adjusted $p$-Values* & $R^{2}$ value** & Nucleotide Variation & Distance to nearest gene $(\mathrm{bp})^{* * *}$ & Nearest Gene ID \\
\hline HSt_SFW & S2_73084591 & 0.02 & 14.71 & $\mathrm{C} / \mathrm{T}$ & $(-) 900$ & Sb02g038910 \\
\hline HSt_SFW & S2_73084594 & 0.02 & 14.60 & $\mathrm{C} / \mathrm{T}$ & $(-) 903$ & Sb02g038910 \\
\hline HSt_SFW & S2_73084593 & 0.02 & -14.71 & $\mathrm{G} / \mathrm{C}$ & $(-) 902$ & Sb02g038910 \\
\hline HSt_SFW & S2_73084596 & 0.02 & -14.71 & G/A & $(-) 905$ & Sb02g038910 \\
\hline HSt_SFW & S6_46226536 & 0.02 & -10.48 & $\mathrm{G} / \mathrm{A}$ & $(+) 847$ & Sb06g017060 \\
\hline HSt_SFW & S2_73084592 & 0.02 & 14.60 & $A / G$ & $(-) 901$ & Sb02g038910 \\
\hline HSt_SFW & S5_19670409 & 0.02 & -15.00 & $\mathrm{G} / \mathrm{A}$ & - & Sb05g009740 \\
\hline HSt_SL & S6_45982131 & 0.07 & 8.69 & $\mathrm{~A} / \mathrm{G}$ & $(-) 318$ & Sb06g016880 \\
\hline HSt_SL & S6_46194160 & 0.07 & -7.96 & $\mathrm{G} / \mathrm{A}$ & $(-) 127$ & Sb06g017025 \\
\hline HSt_SL & S3_1638378 & 0.07 & -24.38 & $\mathrm{~T} / \mathrm{G}$ & 302 & Sb03g001820 \\
\hline HSt_ChIB_W-1 & S4_48000182 & 0.12 & 20.89 & $\mathrm{G} / \mathrm{A}$ & - & Sb04g020520 \\
\hline HSt_ChIB_W ${ }^{-1}$ & S4_48000349 & 0.13 & 20.39 & $\mathrm{G} / \mathrm{A}$ & - & Sb04g020520 \\
\hline
\end{tabular}

*False Discovery Rate (FDR) values for the significantly associated SNP at $p$-value of $1 \mathrm{E}-06$

**Percent trait variation explained by the associated SNPs

***Distance to the nearest annotated gene coordinates in the reference genome 
Table $\mathbf{5}$ List of candidate genes identified in the study based on proximity to the significant markers identified through GWAS analysis and their description or function obtained from gramene(ww.gramene.org) and phytozome (www.phytozome.net) databases

\begin{tabular}{|c|c|}
\hline Gene ID & Annotation \\
\hline Sb01g009310 & methyltransferases \\
\hline Sb02g022120 & HAESA-like 1 \\
\hline Sb02g023140 & Cupredoxin superfamily protein \\
\hline Sb02g023120 & $\begin{array}{l}\text { P-loop containing nucleoside triphosphate } \\
\text { hydrolases superfamily protein }\end{array}$ \\
\hline Sb02g022140 & Unknown \\
\hline Sb02g038300 & Saccharopine dehydrogenase \\
\hline Sb02g038630 & Unknown \\
\hline Sb02g039680 & alpha/beta-Hydrolases superfamily protein \\
\hline Sb02g042450 & Pentatricopeptide repeat (PPR) superfamily protein \\
\hline Sb03g013220 & Peroxidase superfamily protein \\
\hline Sb03g023720 & Expressed Protein \\
\hline Sb03g031320 & splicing factor-related \\
\hline Sb04g030940 & LisH/CRA/RING-U-box domains-containing protein \\
\hline Sb05g001215 & myb domain protein 61 \\
\hline Sb06g002880 & electron transfer flavor protein beta \\
\hline Sb06g015560 & weakly similar to H0717B12.8 protein \\
\hline Sb06g024740 & $\begin{array}{l}\text { Nucleotide-diphospho-sugar transferases } \\
\text { superfamily protein }\end{array}$ \\
\hline Sb06g024820 & GRAS family transcription factor \\
\hline Sb06g024943 & expressed protein \\
\hline Sb06g024960 & UDP-Glycosyltransferase superfamily protein \\
\hline Sb06g025040 & $\begin{array}{l}\text { basic helix-loop-helix (bHLH) DNA-binding } \\
\text { superfamily protein }\end{array}$ \\
\hline Sb06g025060 & $\begin{array}{l}\text { basic helix-loop-helix (bHLH) DNA-binding } \\
\text { superfamily protein }\end{array}$ \\
\hline Sb06g028370 & AICARFT/IMPCHase bienzyme family protein \\
\hline Sb06g028380 & K+ uptake permease 10 \\
\hline Sb06g028540 & similar to Putative uncharacterized protein \\
\hline Sb09g006020 & Actin-like ATPase superfamily protein \\
\hline Sb04g020520 & exocyst subunit exo70 family protein F1 \\
\hline Sb02g038910 & Pectin lyase-like superfamily protein \\
\hline Sb06g017060 & homeobox protein 22 \\
\hline Sb05g009740 & expressed protein \\
\hline Sb06g016880 & magnesium transporter 4 \\
\hline Sb06g017025 & Protein of unknown function (DUF668) \\
\hline Sb03g001820 & GDSL-like Lipase/Acylhydrolase superfamily protein \\
\hline
\end{tabular}

coleoptile color [27], which was a few hundred thousand nucleotides apart from the $b H L H$ gene ( $\mathrm{Sb06g025040)}$ as in the report of Morris et al. [36]. In the current study, distinct SNPs found in Sb06g025040 (-440 and -449) associated with quantitative measures of anthocyanin could be placed upstream of the putative $b H L H$ regulatory gene. This variant could potentially be present in the cis-regulatory regions of the transcription factor Sb06g025040 and could be involved in the regulation of anthocyanin levels for maintaining seedling vigor during stress conditions.

For associated variation under heat stress conditions, we found candidate genes with possible functions as

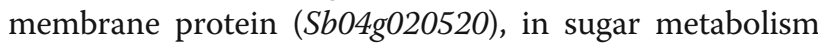
(Sb02g038910), as transcription factor (Sb06g017060), as proteasome (Sb05g009740), as ion transporter (Sb06g016880), and in lipid metabolism (Sb03g001820). The shoot fresh weight was associated with sugar metabolism, proteasome, and ion transporter genes. $\mathrm{K}^{+}$ion transporter genes are involved in programmed cell death and metabolic adjustments [46], whereas proteasomes are known to affect the heat sensitivity in Arabidopsis [47].

In this study, although the genomic analysis showed no overlap between associated regions, the genes involved in tolerance to thermal stress were related. Many of the associations were found close to genes related to membrane transport and sugar metabolism, all of which have potential roles in different stress responses. Therefore, many of the associations observed in our study are suggestive of a coordinated response in sorghum seedling during thermal stress. Previous reports in research have suggested that response to cold and heat stresses are coordinated processes between primary and secondary metabolites and transporters [48-50].

\section{Validation of loci in a germplasm}

The validation of significant SNPs was performed in nine sorghum lines to develop markers for potential use in breeding for thermal stress tolerance. Here, we focused on loci associated with seedling cold tolerance traits in a set of breeding lines with their varying tolerance/sensitivity to cold stress. Towards this end, allele-specific KASP primers were designed for each SNP and used for germplasm genotyping. The results showed that nine of 29 associated SNPs consistently differentiate at least two susceptible lines from the tolerant lines (Additional file 3). These nine variants could be the putative haplotype present in the sorghum that conditions tolerance cold response. These haplotypes were associated with three different traits (anthocyanin levels, shoot and root fresh weights) measured under cold stress. However, further studies are needed to establish any causal relation of these markers to actual tolerance or susceptibility response.

\section{Co-expression modules and expression patterns}

The genes associated with the measured traits in this study could serve as a basis for exploring the thermal stress responsive mechanisms, and therefore it is 
important to evaluate the regulation and expression of the their gene networks. As it is difficult to evaluate all traits or metabolites affected by stress, expression networks can provide a logical approach towards identifying genes which otherwise could not be detected in GWAS analysis due to limitations in markers density or panel size. In this study the co-expression networks for each of the genes associated with the traits measured under stress were retrieved from http://sorghum.riken.jp/morokoshi/ [51] to decipher biochemical pathways or gene regulatory networks related to significant SNPs (Additional file 4).

We selected a few genes and their networks to understand their role in cold stress. Sb06g015560 and Sb06g028370 are involved in amino acid biosynthesis based on their gene networks whereas Sb03g031320 is functionally associated with spliceosome. The gene Sb06g024960 is a UDP-Glycosyltransferase superfamily protein involved in zeatin biosynthesis and was negatively associated with the anthocyanin levels. Zeatin biosynthesis genes have been previously reported to be involved in defense mechanism upon cold stress [52, 53]. Cis-zeatintype cytokinins are known to regulate the plant growth and the responses to environmental changes [54].

Similarly, S5_19670409 associates with the gene Sb05g009740 and has a negative effect on fresh shoot weight upon heat stress. Sb05g009740 has no assigned function but the genes in its network belonged to the proteasome and RNA transport. It is reported that in Arabidopsis, proteasome subunit mutants limit $26 \mathrm{~S}$ proteasome capacity within the cell and can cause heat shock hypersensitivity, and reduced cell division rates [47]. This suggests that Sb05g009740 and its network of genes are associated with the fresh shoot weight during heat stress.

We also evaluated co-expression network of $\mathrm{Sb06g025040}$ $(b H L H)$ and found that the genes in the network were involved in sugar biosynthesis and transport (Fig. 5). It has been shown that in higher plants, the anthocyanin pathway is regulated by a suite of transcription factors including MYB, $b H L H$, and WD repeat proteins [55-57]. Studies have also reported that the induction of anthocyanin and flavonoid biosynthesis can promote accumulation of metabolites such as sugars and hormones $[58,59]$.

Based on these networks of the genes, we likewise determined if any differences were found in the expression of the member genes in previous abiotic stress studies in sorghum. To do this, we examined the normalized FPKM values for the associated genes from a RNASeq experiment by Chopra et al. [23] and found that six of the 32 genes showed differential response upon cold stress between the susceptible and tolerant genotypes (Additional file 5). The SNPs associated with the differentially expressed genes Sb06g025040, Sb06g015560,

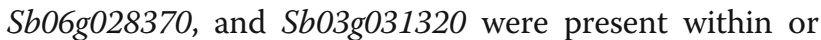
in very close proximity to the member gene itself
(Tables 3 and 4). More importantly, we were able to confirm nucleotide differences between the cold tolerant and susceptible genotypes of sorghum.

Since the differences of haplotype and expression levels were significant for four of the associated genes, we proceeded to to validate their expression levels. We selected Sb06g025040 transcription factor to validate the expression as the mutation linked to the gene could be in cis-regulatory region. The expression analysis confirmed that gene $S b 06 g 025040$ was relatively upregulated in the tolerant genotype (Fig. 6) upon cold stress. However, the specific role of the gene in cold tolerance will require further molecular characterization. To evaluate if other genes involved in the network of Sb06g025040 were also affected by cold stress, we selected three other genes (Sb03g012390, Sb06g023760, and Sb04g035790) that were affiliated with $S b 06 g 025040$. Similar expression patterns were observed between the tolerant and susceptible lines during cold stress (Fig. 6), suggesting a possible role of these genes in cold tolerance of sorghum seedlings. From these results we can propose that Sb06g025040 and genes within its network are strongly associated with cold tolerance mechanisms. Similarly, other genes such as Sb06g015560, Sb06g028370, and Sb03g031320 and their networks can be evaluated to determine their role in cold tolerance.

We also utilized existing ethyl methyl sulfonate (EMS)- mutants to evaluate effects of induced variation in the associated genes identified. Fortuitously, EMSinduced mutants for Sb06g025040 and Sb03g012930 genes from the above network are available from sorghum mutant library [60] for evaluation. Briefly, the ARS207 mutant line had non-synonymous mutation in Sb06g025040, and the ARS137 mutant had a nonsynonymous mutation in Sb03g012930 [60]. We performed expression analysis on these mutants to determine their effect on gene expression. On performing qRT-PCR expression analysis on the mutants compared to wild-type, we found down-regulation of Sb06g025040 in ARS207, but no differences in qRT-PCR data was observed in the ARS137 for Sb03g012930 (Fig. 6). However, further experiments are required to characterize and understand the functional aspects of these differential gene expression patterns.

\section{Conclusions}

A combined investigation involving seedling traits and metabolite phenotyping, aided by genomics based platforms, identified a number of key associations and their complex network of genes underlying the response of sorghum seedlings to cold and heat stresses. Many of the associated SNPs with seedling traits were within or in very close proximity to stress responsive genes. The evaluation of haplotype differences in selected tolerant 


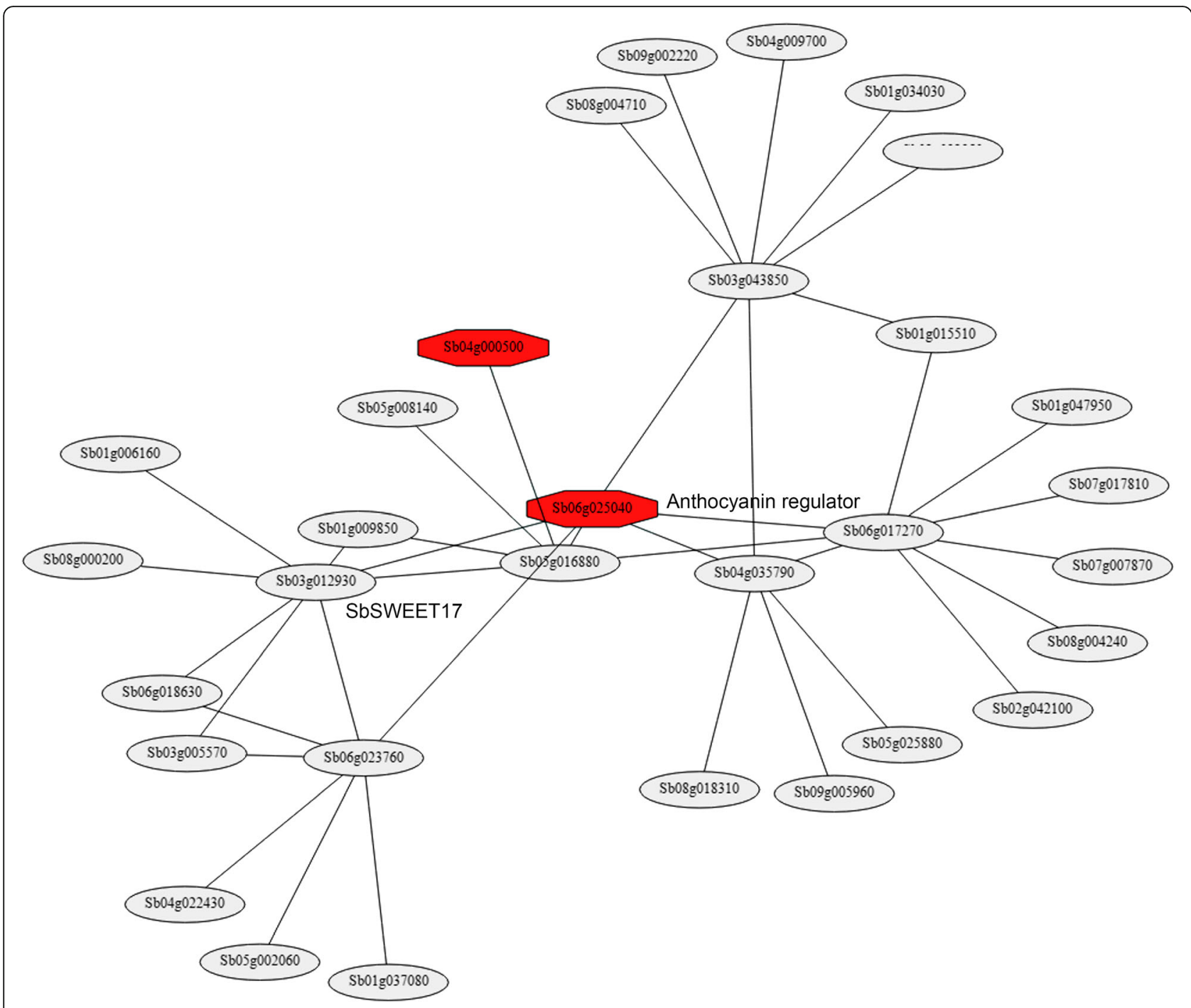

Fig. 5 Co-expression module for Sb06g025040, one of the associated genes with anthocyanin level under cold stress in sorghum association panel

and susceptible genotypes for select SNP markers associated with trait variation under cold stress can serve as a possible tool for marker assisted breeding in sorghum. Differential gene expression during thermal stress for the candidate genes tagged aided in assessing whether the haplotypes identified here would be useful in understanding their role for molecular characterization. Finally, we suggest that the application of expression networks along with RNAseq and GWAS analysis, as highlighted in this study, provides a strong approach to

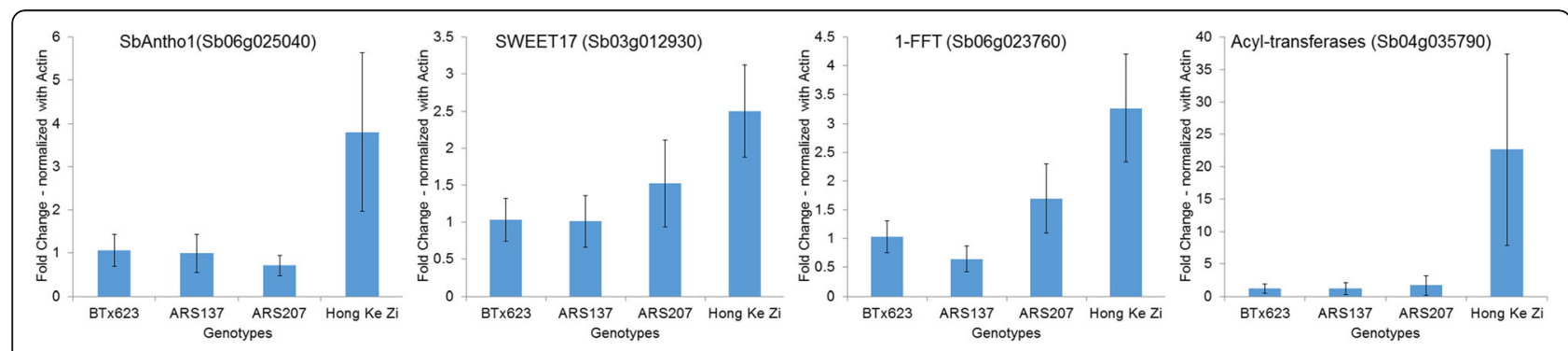

Fig. 6 Quantitative-PCR analysis of genes in co-expression network of Sb06g025040 between cold tolerant (Hong Ke Zi), susceptible line (BTx623), EMS mutants ARS137 and ARS207 
elucidate molecular mechanism involved in thermal and other abiotic stress responses in cereal crops.

\section{Methods}

Plant materials and genotype data

A total of 300 sorghum accessions from the U.S. sorghum association panel- previously described [61], were used in the study (available through the active sorghum germplasm collection at www.ars-grin.gov). The panel is composed of 198 sorghum conversion lines, 46 elite inbreds, and 56 historical accessions of sorghum. The lines are diverse and also represents the major races (kafir, durra, caudatum and bicolor) and working groups of sorghum.

We utilized the community genotype data to perform genome-wide association analysis (www.morrislab.org/ data). A total of 265,487 SNPs based on genotype-bysequencing (GBS) analyses that corresponds to variation in 27,412 annotated genes were utilized [33]. Previous studies demonstrated that this panel and genotype data has sufficient power to dissect complex traits using such populations, including grain yield [62], plant architecture [63] and seed micronutrient composition [64] among other traits.

\section{Growth conditions and phenotypic evaluation}

Evaluation of traits was performed under controlled conditions, where accessions were planted in ragdoll set up in a Mason jar filled with $300 \mathrm{ml}$ of deionized water at constant $14{ }^{\circ} \mathrm{C}$ for chilling stress using controlled chamber cabinets (Percival growth cabinets). Each entry was represented by four replicates, and each replicate consist of five seedlings in a mason jar. A completely randomized design was used to set up the experiment. The seedlings were allowed to grow under $24 \mathrm{~h}$ light conditions for 7 days. The experiments were conducted in batches of 100 entries to facilitate handling of the large number of accessions in SAP. The following traits were evaluated for the entries of the association panel under chilling stress; shoot fresh weight (SFW) and root fresh weight (RFW), shoot length (SL) and root length (RL) and anthocyanin level (Anth_W ${ }^{-1}$ ). Anthocyanin was extracted from the finely ground shoot of 3 pooled seedlings using $1.0 \mathrm{~mL}$ of acidic methanol ( $80 \%$ methanol, $0.01 \mathrm{M} \mathrm{HCL}$ ) for $24 \mathrm{~h}$ in the dark. Anthocyanin content was estimated based on absorbance of methanolic extract at $530 \mathrm{~nm}$. Levels of anthocyanin were expressed as absorbance at $530 \mathrm{~nm}$ per $\mathrm{mg}$ fresh weight.

Heat Stress was evaluated at $37{ }^{\circ} \mathrm{C}$ in the Percival growth cabinets for 7 days. Each entry was represented by four replicates, and each replicate consist of five seedlings in a mason jar. A completely randomized design was used to set up the experiment. The seedlings were allowed to grow under 12/12 h light-dark conditions for 7 days. Shoot fresh weight (SFW), root fresh weight
(RFW), shoot length (SL), and root length (RL) were measured at 7 days after planting. Chlorophyll was extracted from the fresh shoot of three pooled seedlings using $80 \%$ acetone and centrifuged at 10,00 rpm. Absorbance of resulting supernatant was determined at $470 \mathrm{~nm}, 646 \mathrm{~nm}$ and $663 \mathrm{~nm}$ for each entry.

\section{Association analyses}

Genome-wide association analysis was performed using CMLM in combination with SUPER model to determine marker-trait associations. The compressed mixed linear model (CMLM) involves genetic marker-based kinship matrix modeling of random effects used jointly with population structure estimated by principal components analysis (PCA) to model fixed effects [34, 65, 66]. SUPER model [67] extracts a small subset of SNPs from CMLM and uses them in FaST-LMM method. This method increases statistical power and is computationally advantageous. The compression level and optimal number of principal components that adequately explain population structure were previously determined by the Genomic Association and Prediction Integrated Tool [34]. Log quantile-quantile (QQ) $p$-value plots for 265,487 single SNP tests of association implied that there were few systematic sources of spurious association using CMLM with SUPER model. As several studies have suggested varying number of $L D$ blocks in sorghum, $L D$ range of 3-30 kb was used for the analysis.

\section{DNA isolation, primer design and genotyping of SNPs}

To validate bi-allelic SNPs in a total of nine sorghum genotypes, genomic DNA was isolated from seed samples using Qaigen miniprep plant kit. About 150 bp upstream and downstream of the SNP loci were extracted from the available genome sequence for use in primer design. These sequences were passed through primer3 program with the option of allele-specific and flanking primer method and the size range of 60-100 nucleotides (http://probes.pw.usda.gov/ cgi-bin/batchprimer3/batchprimer3.cgi). Primer sequences are provided as an Additional file 6. End point genotyping using KASP was performed as previously described in Chopra et al. [23].

\section{Genes in QTL regions and Co-expression network}

Associated SNPs were scanned for the nearby genes in the genomic coordinates using gramene biomart (www.gramene.org) and phytozome v.10 (www.phytozome.net). Closest genes in the upstream or downstream of $20 \mathrm{~kb}$ were selected and the respective annotations were obtained for each of the genes. Co-expression networks for each of the genes associated was retrieved using the expression database developed by Makita et al. [54]. Top twenty genes in the network for each of the associations have been attached as an Additional file 3. 


\section{Expression analysis using qRT-PCR}

For this study 20 seeds for each of the cultivar Hong Ke $\mathrm{Zi}$ (cold tolerant) and BTx623 (cold sensitive) were planted in ragdoll set up under cold stress temperatures. The temperatures were continuous $14{ }^{\circ} \mathrm{C}$ for cold stress using Conviron walk-in growth cabinets. The seedlings were allowed to grow under $14 \mathrm{~h}$ light $/ 10 \mathrm{~h}$ dark conditions. Leaf tissue samples for RNA extraction were obtained from five seedlings per replicate for Hong $\mathrm{Ke} \mathrm{Zi}$ and BTx623. Three replicates were extracted separately using the TRIzol reagent and company recommended protocols (Life Technologies, Grand Island, NY). The total RNA samples from each replicate were quantified using Nano Drop and subsequently purified using the RNAeasy mini clean up kit (Qiagen, Valencia, CA). To evaluate the expression differences observed, qRT-PCR primers were designed for four selected genes in the expression module using primer3 (Additional file 7) and sorghum actin gene was used for normalization. Briefly, qRT-PCR was performed using copy-DNA libraries generated from the total RNA using Invitrogen cDNA synthesis kit (Invitrogen, Grand Island, NY). qRT-PCR was performed on the cDNA of the four samples with 3 biological and 3 technical replicates using SybrGreen on LightCycler 480.

\section{Additional files}

Additional file 1: Pearson's correlation among traits measured with thermal stress application at seedling stage. (XLSX $10 \mathrm{~kb}$ )

Additional file 2: Phenotypic measurements of seedling upon heat and cold stress on 300 sorghum association panel. (XLSX 50 kb)

Additional file 3: Validation of SNPs in nine sorghum lines to determine the haplotypes for cold tolerance. (XLSX $10 \mathrm{~kb}$ )

Additional file 4: List of top twenty genes in the network of associated genes derived from sorghum gene network porvided by Makita et al. [51]. (XLSX $40 \mathrm{~kb})$

Additional file 5: List of related RNASeq normalized FPKM values for susceptible (BTx623) and tolerant (Hong Ke Zi) lines during cold stress retrieved from Chopra et al. [20]. (XLSX $10 \mathrm{~kb})$

Additional file 6: Lis of KASP primers sequences designed for the significant SNPS associated with varaition of seedling traits under thermal stress. (XLSX $10 \mathrm{~kb}$ )

Additional file 7: List of $\mathrm{qRT}-\mathrm{PCR}$ primers used in expression analysis of the selected genes in this study. (XLSX $9 \mathrm{~kb}$ )

\section{Abbreviations}

AOV: Analysis of variance; bHLH: Basic-helix-loop-helix (bHLH);

CMLM: Compressed mixed linear model; FDR: False discovery rate; GWAS: Genome-wide association studies; kb: Kilobase of nucleotides;

SAP: Sorghum association panel; SNP: Single nucleotide polymorphism

\section{Acknowledgements}

We thank Julia V. Sanchez, Jacobo Sanchez, and Halee Hughes for technical support.

\section{Funding}

This work was supported by USDA-ARS CRIS project 6208-21000-020-00D and the United Sorghum Checkoff Program (USCP) grant on "Genetic Enhancement of Sorghums". Ratan Chopra is funded through the USCP extramural grant,
Nicholas Gladman is supported by Class of 2015 Postdoctoral Research Grant from USDA-ARS.

Availability of data and materials

The data sets supporting the results of this publication are cited (and their availability verified thru their website address) or are included within the article and its Additional files.

\section{Author contributions}

$J B$ and $G B$ designed and directed the research; RC analyzed the data; $R C$ \& GB wrote the manuscript with input from all authors; NG and ZX contributed new germplasm and techniques. All authors edited and agreed on the final manuscript.

\section{Competing interests}

The authors declare that they have no competing interests.

\section{Consent for publication}

Not applicable.

Ethics approval and consent to participate

Not applicable.

\section{Disclaimer Statement}

Mention of trade names or commercial products in this publication is solely for the purpose of providing specific information and does not imply recommendation or endorsement by the U.S. Department of Agriculture. USDA is an equal opportunity provider and employer.

Received: 1 July 2016 Accepted: 23 December 2016

Published online: 13 January 2017

\section{References}

1. Willis CG, Ruhfel B, Primack RB, Miller-Rushing AJ, Davis CC. Phylogenetic patterns of species loss in Thoreau's woods are driven by climate change. Proc Natl Acad Sci. 2008;105(44):17029-33.

2. Stavang JA, Gallego-Bartolomé J, Gómez MD, Yoshida S, Asami T, Olsen JE, García-Martínez JL, Alabadí D, Blázquez MA. Hormonal regulation of temperature-induced growth in Arabidopsis. Plant J. 2009;60(4):589-601.

3. Kumar SV, Lucyshyn D, Jaeger KE, Alos E, Alvey E, Harberd NP, Wigge PA. Transcription factor PIF4 controls the thermosensory activation of flowering. Nature. 2012;484(7393):242-5.

4. Delouche J, Baskin C. Accelerated ageing techniques for predicting the relative storability of seed lots. Seed Sci Technol. 1973;1:427-52.

5. Apel K, Hirt H. Reactive oxygen species: metabolism, oxidative stress, and signal transduction. Annu Rev Plant Biol. 2004;55(1):373-99.

6. Kaplan F, Kopka J, Haskell DW, Zhao W, Schiller KC, Gatzke N, Sung DY, Guy $\mathrm{CL}$. Exploring the temperature-stress metabolome of Arabidopsis. Plant Physiol. 2004:136(4):4159-68.

7. Marczak Ł, Kachlicki P, Koźniewski P, Skirycz A, Krajewski P, Stobiecki M. Matrix-assisted laser desorption/ionization time-of-flight mass spectrometry monitoring of anthocyanins in extracts from Arabidopsis thaliana leaves. Rapid Commun Mass Spectrom. 2008;22(23):3949-56.

8. Hannah MA, Wiese D, Freund S, Fiehn O, Heyer AG, Hincha DK. Natural genetic variation of freezing tolerance in Arabidopsis. Plant Physiol. 2006; 142(1):98-112.

9. Hannah M, Heyer A, Hincha D. A global survey of gene regulation during cold acclimation in Arabidopsis thaliana. PLoS Genet. 2005;1(2):e26.

10. Korn M, Peterek S, Mock H-P, Heyer AG, Hincha DK. Heterosis in the freezing tolerance, and sugar and flavonoid contents of crosses between Arabidopsis thaliana accessions of widely varying freezing tolerance. Plant Cell Environ. 2008;31(6):813-27.

11. Knoll J, Ejeta G. Marker-assisted selection for early-season cold tolerance in sorghum: QTL validation across populations and environments. Theor Appl Genet. 2008;116:541-53.

12. Burow G, Burke J, Xin Z, Franks C. Genetic dissection of early-season cold tolerance in sorghum (Sorghum bicolor (L.) Moench). Mol Breed. 2011;28: 391-402.

13. Upadhyaya HD, Wang Y-H, Sastry DVSSR, Dwivedi SL, Prasad PW, Burrell AM, Klein RR, Morris GP, Klein PE. Association mapping of germinability and 
seedling vigor in sorghum under controlled low-temperature conditions. Genome. 2016;59:137-45.

14. Yamasaki T, Yamakawa T, Yamane Y, Koike H, Satoh K, Katoh S. Temperature acclimation of photosynthesis and related changes in photosystem ii electron transport in winter wheat. Plant Physiol. 2002;128(3):1087-97.

15. Pastenes C, Horton P. Effect of high temperature on photosynthesis in beans (i. oxygen evolution and chlorophyll fluorescence). Plant Physiol. 1996;112(3):1245-51.

16. Gosavi GU, Jadhav AS, Kale AA, Gadakh SR, Pawar BD, Chimote VP. Effect of heat stress on proline, chlorophyll content, heat shock proteins and antioxidant enzyme activity in sorghum (Sorghum bicolor) at seedlings stage. Indian J Biotechnol. 2014;13(3):356-63.

17. Hasanuzzaman M, Nahar K, Alam M, Roychowdhury R, Fujita M. Physiological, biochemical, and molecular mechanisms of heat stress tolerance in plants. Int J Mol Sci. 2013;14(5):9643.

18. Atkinson NJ, Urwin PE. The interaction of plant biotic and abiotic stresses: from genes to the field. J Exp Bot. 2012;62(10):3523-43.

19. Revilla P, Rodríguez VM, Ordás A, Rincent R, Charcosset A, Giauffret C, Melchinger AE, Schön C-C, Bauer E, Altmann T, et al. Association mapping for cold tolerance in two large maize inbred panels. BMC Plant Biol. 2016;16(1):1-10.

20. Chopra R, Burow G, Hayes C, Emendack Y, Xin Z, Burke J. Transcriptome profiling and validation of gene based single nucleotide polymorphisms (SNPs) in sorghum genotypes with contrasting responses to cold stress. BMC Genomics. 2015;16(1):1-11.

21. Dugas D, Monaco M, Olson A, Klein R, Kumari S, Ware D. Functional annotation of the transcriptome of Sorghum bicolor in response to osmotic stress and abscisic acid. BMC Genomics. 2011; 12. doi: 10.1186/1471-216412-514.

22. Johnson S, Lim F-L, Finkler A, Fromm H, Slabas A, Knight M. Transcriptomic analysis of Sorghum bicolor responding to combined heat and drought stress. BMC Genomics. 2014; 15. doi: 10.1186/1471-2164-15-456.

23. Gelli M, Duo Y, Konda A, Zhang C, Holding D, Dweikat I. Identification of differentially expressed genes between sorghum genotypes with contrasting nitrogen stress tolerance by genome-wide transcriptional profiling. BMC Genomics. 2014; 15. doi: 10.1186/1471-2164-15-179.

24. Sukumaran S, Xiang W, Bean SR, Pedersen JF, Kresovich S, Tuinstra MR, Tesso TT, Hamblin MT, Yu J. Association mapping for grain quality in a diverse sorghum collection. Plant Genome. 2012:5(3):126-35.

25. Upadhyaya HD, Wang Y-H, Gowda CLL, Sharma S. Association mapping of maturity and plant height using SNP markers with the sorghum mini core collection. Theoretical and Applied Genetics. 2014; 126. doi:10.1007/s00122013-2113-X.

26. Adeyanju A, Little C, Yu J, Tesso T. Genome-wide association study on resistance to stalk rot diseases in grain sorghum. G3: Genes|Genomes|Genet. 2015;5(6):1165-75.

27. Morris GP, Rhodes DH, Brenton Z, Ramu P, Thayil VM, Deshpande S, Hash $\mathrm{CT}$, Acharya C, Mitchell SE, Buckler ES, et al. Dissecting genome-wide association signals for loss-of-function phenotypes in sorghum flavonoid pigmentation traits. G3: Genes|Genomes|Genet. 2013;3(11):2085-94.

28. Zhang D, Li J, Compton RO, Robertson J, Goff VH, Epps E, Kong W, Kim C, Paterson AH. Comparative genetics of seed size traits in divergent cereal lineages represented by sorghum (panicoidae) and rice (oryzoidae). G3: Genes|Genomes|Genet. 2015;5(6):1117-28.

29. Hayes CM, Burow GB, Brown PJ, Thurber C, Xin Z, Burke JJ. Natural variation in synthesis and catabolism genes influences dhurrin content in sorghum. Plant Genome. 2015;8. doi:10.3835/plantgenome2014.09.0048.

30. Balota M, Payne WA, Veeragoni SK, Stewart BA, Rosenow DT. Respiration and its relationship to germination, emergence, and early growth under cool temperatures in sorghum. Crop Sci. 2010;50(4):1414-22.

31. Bekele WA, Fiedler K, Shiringani A, Schnaubelt D, Windpassinger S, Uptmoor R, Friedt W, Snowdon RJ. Unravelling the genetic complexity of sorghum seedling development under low-temperature conditions. Plant Cell Environ. 2014;37(3):707-23.

32. Fiedler K, Bekele WA, Friedt W, Snowdon R, Stützel H, Zacharias A, Uptmoor R. Genetic dissection of the temperature dependent emergence processes in sorghum using a cumulative emergence model and stability parameters. Theor Appl Genet. 2012;125(8):1647-61.

33. Morris GP, Ramu P, Deshpande SP, Hash CT, Shah T, Upadhyaya HD, RieraLizarazu O, Brown PJ, Acharya CB, Mitchell SE, et al. Population genomic and genome-wide association studies of agroclimatic traits in sorghum. Proc Natl Acad Sci. 2013;110(2):453-8.
34. Lipka AE, Tian F, Wang Q, Peiffer J, Li M, Bradbury PJ, Gore MA, Buckler ES, Zhang Z. GAPIT: genome association and prediction integrated tool. Bioinformatics. 2012;28(18):2397-9.

35. Menkir A, Larter EN. Emergence and seedling growth of inbred lines of corn at suboptimal root-zone temperatures. Can J Plant Sci. 1987;67(2): 409-15.

36. Mace ES, Singh V, Oosterom EJ, Hammer GL, Hunt CH, Jordan DR. QTL for nodal root angle in sorghum (Sorghum bicolor L. Moench) co-locate with QTL for traits associated with drought adaptation. Theor Appl Genet. 2011;124(1):97-109.

37. Delouche J, Baskin C. Accelerated ageing techniques for predicting the relative storability of seed lots. Seed Sci Technol. 1973;427-52.

38. Parh DK, Jordan DR, Aitken EAB, Mace ES, Jun-ai P, Mclntyre CL, Godwin ID. QTL analysis of ergot resistance in sorghum. Theor Appl Genet. 2008;117(3):369-82.

39. Shiringani AL, Frisch M, Friedt W. Genetic mapping of QTLs for sugar-related traits in a RIL population of Sorghum bicolor L. Moench. Theor Appl Genet. 2010;121(2):323-36.

40. Zou G, Zhai G, Feng Q, Yan S, Wang A, Zhao Q, Shao J, Zhang Z, Zou J, Han $B$, et al. Identification of QTLs for eight agronomically important traits using an ultra-high-density map based on SNPs generated from high-throughput sequencing in sorghum under contrasting photoperiods. J Exp Bot. 2012; 63(15):5451-62.

41. Huang X-S, Wang W, Zhang Q, Liu J-H. A basic helix-loop-helix transcription factor, PtrbHLH, of Poncirus trifoliata confers cold tolerance and modulates peroxidase-mediated scavenging of hydrogen peroxide. Plant Physiol. 2013; 162(2):1178-94.

42. Peng $\mathrm{H}-\mathrm{h}$, Shan W, Kuang J-f, Lu W-j, Chen J-y. Molecular characterization of cold-responsive basic helix-loop-helix transcription factors MabHLHs that interact with MalCE1 in banana fruit. Planta. 2013;238(5):937-53.

43. Feng X-M, Zhao Q, Zhao L-L, Qiao Y, Xie X-B, Li H-F, Yao Y-X, You C-X, Hao $Y$-J. The cold-induced basic helix-loop-helix transcription factor gene MdCIbHLH1encodes an ICE-like protein in apple. BMC Plant Biol. 2012;12(1):1-14.

44. Zhang H, Liu Y, Wen F, Yao D, Wang L, Guo J, Ni L, Zhang A, Tan M, Jiang $\mathrm{M}$. A novel rice $\mathrm{C} 2 \mathrm{H} 2$-type zinc finger protein, ZFP36, is a key player involved in abscisic acid-induced antioxidant defence and oxidative stress tolerance in rice. J Exp Bot. 2014;65(20):5795-809. doi:10.1093/jxb/eru313.

45. Yu G, Jiang L, Ma X, Xu Z, Liu M, Shan S. A Soybean C2H2-Type zinc finger gene GmZF1 Enhanced cold tolerance in transgenic Arabidopsis. PLoS One. 2014;9(10):e109399.

46. Demidchik V, Straltsova D, Medvedev SS, Pozhvanov GA, Sokolik A, Yurin V. Stress-induced electrolyte leakage: the role of $\mathrm{K}+$-permeable channels and involvement in programmed cell death and metabolic adjustment. J Exp Bot. 2014;65(5):1259-70.

47. Kurepa J, Wang S, Li Y, Smalle J. Proteasome regulation, plant growth and stress tolerance. Plant Signal Behav. 2009;4(10):924-7.

48. Seki M, Narusaka M, Ishida J, Nanjo T, Fujita M, Oono Y, Kamiya A, Nakajima M, Enju A, Sakurai T, et al. Monitoring the expression profiles of 7000 Arabidopsis genes under drought, cold and high-salinity stresses using a full-length cDNA microarray. Plant J. 2002;31(3):279-92.

49. Shaik R, Ramakrishna W. Machine learning approaches distinguish multiple stress conditions using stress-responsive genes and identify candidate genes for broad resistance in rice. Plant Physiol. 2014;164(1):481-95.

50. Shaik R, Ramakrishna W. Genes and co-expression modules common to drought and bacterial stress responses in Arabidopsis and rice. PLOS ONE. 2013;8(10):e77261.

51. Makita Y, Shimada S, Kawashima M, Kondou-Kuriyama T, Toyoda T, Matsui M. MOROKOSHI: transcriptome database in Sorghum bicolor. Plant Cell Physiol. 2015;56(1):e6.

52. Lei $X$, Xiao $Y$, Xia W, Mason AS, Yang $Y$, Ma Z, Peng M. RNA-Seq analysis of oil palm under cold stress reveals a different C-repeat binding factor (CBF) mediated gene expression pattern in elaeis guineensis compared to other species. PLOS ONE. 2014;9(12):e114482.

53. O'Brien JA, Benková E. Cytokinin cross-talking during biotic and abiotic stress responses. Front Plant Sci. 2013:4:451. doi:10.3389/fpls. 2013.00451

54. Schäfer M, Meza-Canales ID, Navarro-Quezada A, Brütting C, Vanková R, Baldwin IT, Meldau S. Cytokinin levels and signaling respond to wounding and the perception of herbivore elicitors in Nicotiana attenuata. J Integr Plant Biol. 2015;57(2):198-212. 
55. Lepiniec L, Debeaujon I, Routaboul J-M, Baudry A, Pourcel L, Nesi N, Caboche M. Genetics and biochemistry of seed flavonoids. Annu Rev Plant Biol. 2006;57(1):405-30.

56. Gonzalez A, Zhao M, Leavitt JM, Lloyd AM. Regulation of the anthocyanin biosynthetic pathway by the TTG1/bHLH/Myb transcriptional complex in Arabidopsis seedlings. Plant J. 2008:53(5):814-27.

57. Lotkowska ME, Tohge T, Fernie AR, Xue G-P, Balazadeh S, Mueller-Roeber B. The Arabidopsis transcription factor MYB112 promotes anthocyanin formation during salinity and under high light stress. Plant Physiol. 2015 169(3):1862-80.

58. Teng S, Keurentjes J, Bentsink L, Koornneef M, Smeekens S. Sucrose-specific induction of anthocyanin biosynthesis in Arabidopsis requires the MYB75/ PAP1 gene. Plant Physiol. 2005;139(4):1840-52.

59. Tarkowski LP, Van den Ende W. Cold tolerance triggered by soluble sugars: a multifaceted countermeasure. Front Plant Sci. 2015; 6. doi:10.3389/fpls. 2015.00203.

60. Jiao Y, Burke JJ, Chopra R, Burow G, Chen J, Wang B, Hayes C, Emendack Y, Ware $D$, Xin Z. A sorghum mutant resource as an efficient platform for gene discovery in grasses. Plant Cell. 2016;28(7):1551-62.

61. Casa AM, Pressoir G, Brown PJ, Mitchell SE, Rooney WL, Tuinstra MR, Franks $\mathrm{CD}$, Kresovich S. Community resources and strategies for association mapping in Sorghum. Crop Sci. 2008;48(1):30-40.

62. Boyles RE, Cooper EA, Myers MT, Brenton Z, Rauh BL, Morris GP, Kresovich S: Genome-wide association studies of grain yield components in diverse sorghum germplasm. Plant Genome. 2016; 9(2). doi:10.3835/ plantgenome2015.09.0091.

63. Zhao J, Mantilla Perez MB, Hu J, Salas Fernandez MG: Genome-wide association study for nine plant architecture traits in sorghum. The Plant Genome. 2016; 9(2). doi:10.3835/plantgenome2015.06.0044.

64. Shakoor N, Ziegler G, Dilkes BP, Brenton Z, Boyles R, Connolly EL, Kresovich $S$, Baxter I. Integration of experiments across diverse environments identifies the genetic determinants of variation in Sorghum bicolor seed element composition. Plant Physiol. 2016;170(4):1989-98.

65. Bradbury PJ, Zhang Z, Kroon DE, Casstevens TM, Ramdoss Y, Buckler ES. TASSEL: software for association mapping of complex traits in diverse samples. Bioinformatics. 2007;23(19):2633-5.

66. Zhang Z, Ersoz E, Lai C-Q, Todhunter RJ, Tiwari HK, Gore MA, Bradbury PJ, Yu J, Arnett DK, Ordovas JM, et al. Mixed linear model approach adapted for genome-wide association studies. Nat Genet. 2010;42(4):355-60.

67. Wang Q, Tian F, Pan Y, Buckler ES, Zhang Z. A super powerful method for genome wide association study. PLoS ONE. 2014;9(9):e107684.

\section{Submit your next manuscript to BioMed Central and we will help you at every step:}

- We accept pre-submission inquiries

- Our selector tool helps you to find the most relevant journal

- We provide round the clock customer support

- Convenient online submission

- Thorough peer review

- Inclusion in PubMed and all major indexing services

- Maximum visibility for your research

Submit your manuscript at www.biomedcentral.com/submit

) Biomed Central 